\title{
Influence of growth stresses and material properties on distortion of sawn timber - numerical investigation
}

\author{
Marie JOHANSSON $^{1 *}$, Sigurdur ORMARSSON ${ }^{2}$ \\ ${ }^{1}$ School of Technology and Design, Växjö University, 35195 Växjö, Sweden \\ ${ }^{2}$ Department of Civil Engineering Technical, University of Denmark, 2800 Lyngby, Denmark
}

(Received 28 November 2008; accepted 23 February 2009)

Keywords:

modulus of elasticity /

longitudinal shrinkage /

spiral grain angle /

shape stability
Mots-clés :

module d'élasticité /

retrait longitudinal /

angle du fil /

stabilité de la forme

\begin{abstract}
- The board distortion that occurs during the sawing and the drying process causes major problems in the utilisation of sawn timber. The distortion is highly influenced by parameters such as spiral grain angle, modulus of elasticity, shrinkage, growth stresses and sawing pattern.

- In this study a finite element simulation of log sawing and timber drying was performed to study how these parameters interact to affect board distortion. A total of $81 \operatorname{logs}$ with different material combinations were simulated. From each simulated log four boards with different annual ring orientation were studied.

- The results showed that the elastic modulus, shrinkage coefficient and growth stresses had a large influence on the final bow and spring deformation. After sawing of the log into boards, the release of growth stresses was the main contributor to the bow and spring deformation. For boards with low modulus of elasticity, the bending distortion became larger than for the boards with high modulus of elasticity. The twist deformation was very small after sawing but increased significantly during drying of the boards. The results showed that spiral grain angle and the board location within the log were the main contributors to the twist deformation.
\end{abstract}

Résumé - Influence des contraintes de croissance et des propriétés du matériau sur la déformation des sciages. Analyse numérique.

- La déformation des planches qui se produit au cours du sciage et du séchage conduit à des difficultés importantes pour l'utilisation des sciages. Les déformations sont très dépendantes de paramètres tels que l'angle du fil, le module d'élasticité, les retraits, les contraintes de croissance et le plan de débit. - Dans cette étude nous avons réalisé une simulation par éléments finis du sciage de billons et de leur séchage pour étudier comment ces paramètres interagissent et affectent la distorsion des planches. Nous avons simulé un total de 81 billons avec différentes combinaisons des propriétés du matériau. Pour chaque billon quatre planches sont simulées avec différentes orientations des limites de cernes. - Les résultats montrent que le module d'élasticité, les coefficients des retraits et les contraintes de croissance ont une grande influence sur la courbure finale de la face et sur la courbure de chant. Après le sciage des billons en planches, la libération des contraintes de croissance est le principal contributeur des deux déformations précédentes. Enfin, on montre que l'angle du fil et la position de la planche dans le billon sont les principales causes du gauchissement.

\section{INTRODUCTION}

The lack of shape stability is a major problem for both the saw-mill industry and the building industry. Lack of shape stability causes severe loss of material in the saw-mill industry (Woxblom, 1993). In the building industry a lack of straightness obstructs the building process at the building site and leads to the building industry choosing alternative materials (Eastin et al., 1999; 2001). To change this trend it is necessary for the forest and wood industry to improve the quality of

*Corresponding author: marie.johansson@vxu.se the products in terms of shape stability. With better knowledge of the parameters that cause board distortion, it is possible to find solutions for how to produce sawn timber products of the quality that the end users require.

The board distortion can be divided into three main deformation modes, bow, spring and twist. Bow and spring are the two bending modes. They can be divided into two stages: bow and spring occurring directly after sawing, and the change in bending during moisture content change. Most of the moisture-related bow and spring deformations can be explained by means of the inhomogeneity in axial shrinkage 
(Kliger et al., 1997; 2003; Johansson, 2003; Stanish, 2000). The bow and spring occurring directly after sawing are a result of the redistribution of the growth stresses when the log is sawn into boards (Okuyama and Sasaki, 1979). Growth stresses are stresses that develop progressively during maturation of wood cells in growing trees. The growth stresses are thought to arise when the newly formed wood cell, in the cambium zone, contracts longitudinally due to crystallisation of the cellulose molecules and expands transversally due to lignification (Archer, 1987). Since the new cells are attached to the old cells, a strain constraint develops in the stem, the maturing cells becoming stretched longitudinally and compressed tangentially, whereas the matured cells are exposed to the opposite stress conditions. During the progressive growth of a tree, the wood cells inside the trunk become increasingly compressed in the longitudinal direction. There are many studies performed on the origin of growth stresses, the relationship between different wood properties and growth stress as well as the effect of growth stresses. Two comprehensive literature reviews were made by Archer (1987) and Kubler (1987), newer studies have been performed by for example Alhasani (1999) and Fang et al. (2008). The stress state within the log will affect the distortion occurring directly after sawing, see for example Ormarsson et al. (2008). The residual growth stresses in the boards will affect the size and distribution of drying stresses, and also affect the creep and mechano-sorptive behaviour of the sawn timber during drying.

Twist deformation is mainly caused by transversal shrinkage of the wood material in combination with annual ring curvature and spiral grain angle (Backstrom and Johansson, 2006; Balodis, 1972; Johansson and Kliger, 2002; Mishiro and Booker, 1988; Ormarsson et al., 2000). Timber boards sawn from the area close to the pith (large annual ring curvature) are usually more twisted than boards sawn further away from the pith (Johansson et al., 2001). Large spiral grain angle or a large radial variation in spiral grain angle over the board cross-section will, together with tangential shrinkage, cause the sawn boards to twist (Balodis, 1972; Ormarsson et al., 1999; Stevens and Johnston, 1960). Several models have been developed to describe the twist behaviour of sawn timber (Backstrom and Johansson, 2006; Booker, 2005; Ormarsson et al., 1998; Stevens and Johnston, 1960).

Wood products are strongly affected by both internal characteristics and outside actions. The internal characteristics are material properties and their variation both radially and longitudinally as well as the strong orthotropy. The outside actions are processes such as cutting of logs and sawing of log into boards (release of growth stresses) and forced drying of the boards (moisture content changes). To study all these parameters experimentally is almost impossible; however, simulations using the finite element method can facilitate such a study theoretically. In this study the theory and implementation presented earlier (Ormarsson et al., 1998; Ormarsson and Johansson, 2006) was used to study how two material parameters (longitudinal modulus of elasticity and longitudinal shrinkage coefficient), one state variable (growth stress in the fibre direction) and two geometrical parameters (spiral grain angle and annual ring curvature) influence the board distor-

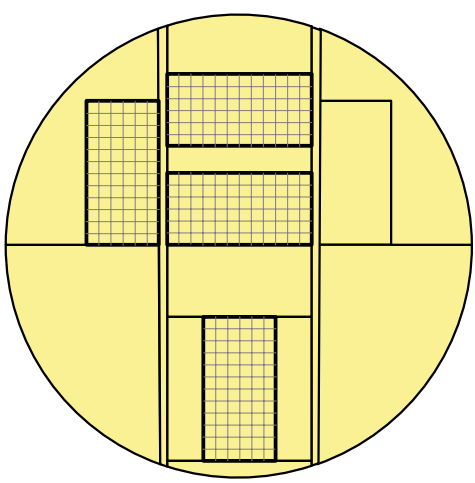

(a)
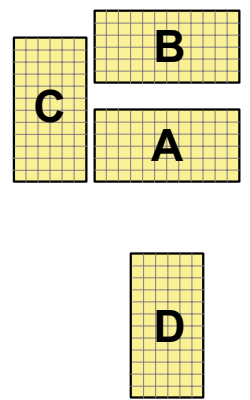

(b)
Figure 1. Deletion of different sets and board positioning in the log as well as board number.

tion directly after sawing and during drying. The study was performed as a factorial study with four parameters: longitudinal elastic modulus, longitudinal shrinkage coefficient, spiral grain angle and longitudinal growth stress. Based on experimental findings, three radial variations were estimated for each of the parameters, and this led to $81 \operatorname{logs}$ with different combinations of material parameters. For each log, the bow, spring and twist deformations were studied for four boards with different annual ring patterns both directly after sawing and after drying. The aim was to study how growth stresses affect the board distortion and how they interact with the other material parameters.

\section{MATERIAL AND METHODS}

\subsection{FEM model}

The log studied had a length of $2500 \mathrm{~mm}$ with a diameter of $320 \mathrm{~mm}$. For each $\log$, it was decided to simulate the distortion of four boards sawn from different locations in the log; see Figure 1. The cross-section dimensions of the boards were $50 \times 100 \mathrm{~mm}$. For the board type A, the pith was running along the middle of one flat surface, whereas the other three boards (called B, C, and D) had different ring orientations but an equal distance $(100 \mathrm{~mm})$ from the board centre to the pith; see Figure 1. The rectangular mesh pattern of the boards $(6 \times 12$ elements over the cross-section) is shown in Figure $1 \mathrm{~b}$. The number of elements along the board was set to 40 . The growth stresses were applied to the log as an initial stress field, before crosscutting the log. In the first modelling step, stress equilibrium for the $\log$ was achieved. In the subsequent steps, different parts of the log were removed to free the boards from the log; see Figure 1b. New boundary conditions were also added to the free boards just to avoid rigid body movements of the boards. During each step, a new stress equilibrium was reached. After the sawing, a slow drying process was simulated to dry the boards from $27 \% \mathrm{MC}$ down to $10 \% \mathrm{MC}$.

\subsection{Material data}

For a three-dimensional distortion model of inhomogeneous orthotropic material, much input data is needed. In this study the material was assumed to be homogeneous (with constant values) regarding 


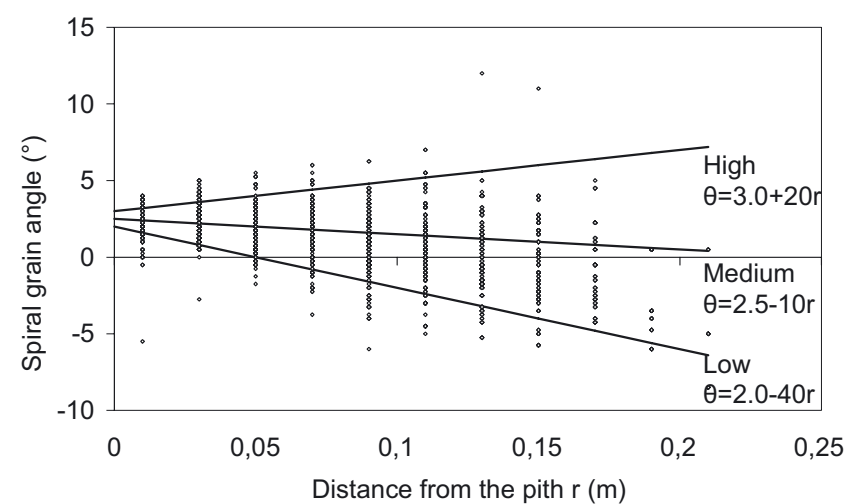

(a)

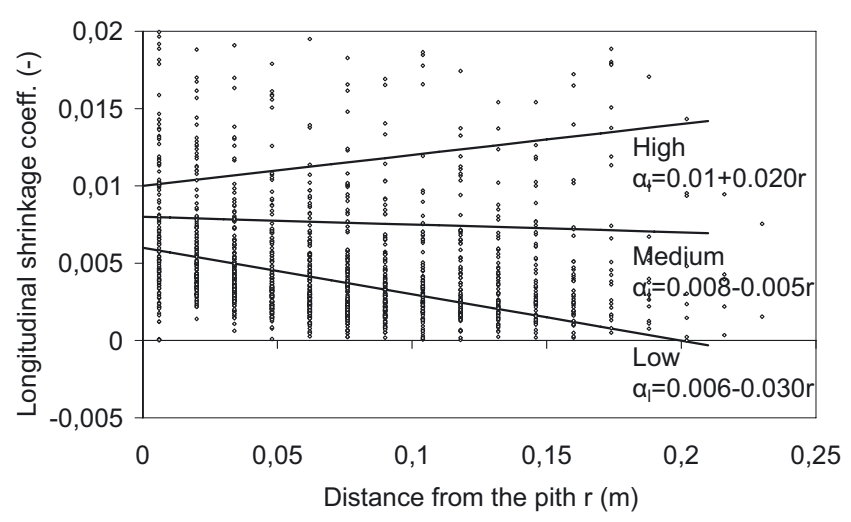

(b)

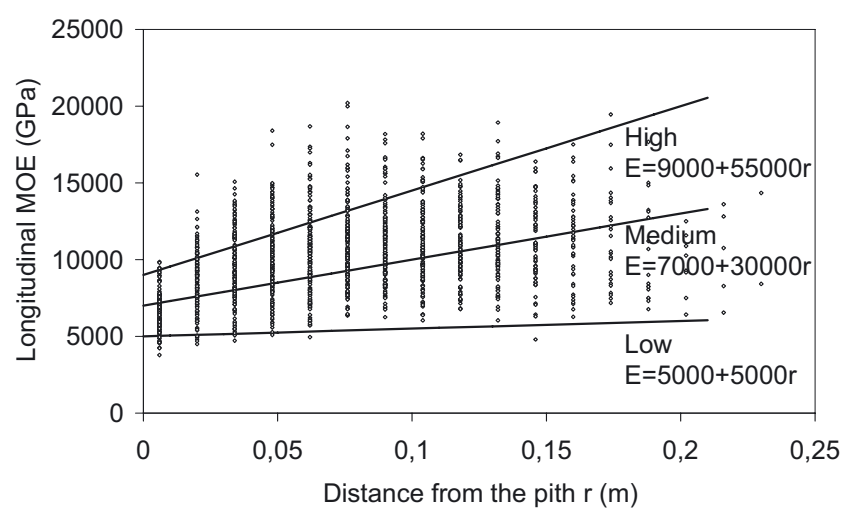

(c)

Figure 2. Radial variation in (a) spiral grain angle, (b) longitudinal shrinkage coefficient and (c) modulus of elasticity (experimental data from 120 Norway spruce trees and linear curves used as input data in the parametric study).

most of the material parameters The material data used in the present simulations are representative for Norway spruce (Picea abies) (see supplemented data, Tab. A).

In the factorial design, three different radial variations were studied for the four parameters: spiral grain angle, longitudinal shrinkage coefficient, modulus of elasticity and growth stresses. The variations used for the first three parameters were based on experimental data for Norway spruce grown in Scandinavia (Dahlblom et al., 2000; Moore and Maun, 1998). Figure 2 displays the range in measured

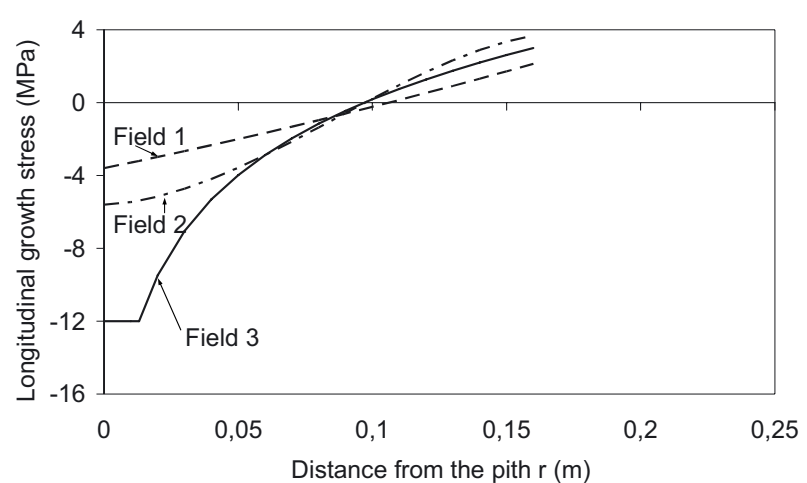

Figure 3. Three different radial variations in growth stresses used in the parametric study.

values for these parameters collected from 120 Norway spruce trees from Sweden. Three linear equations have been adopted to represent a normal (medium) radial variation as well as one high and one low boundary curve for the studied parameters; see Figure 2.

Three variations were used for the variation in growth stress in the fibre direction, see Figure 3. For Norway spruce, very few experimental results on growth stresses are available. In a study conducted by Alhasani (1999), deformations of small sticks caused by redistribution of growth stresses were measured for 11 different Norway spruce trees grown in southern Sweden. The average curve for radial growth stress variation from these trees was chosen as one of the curves used in the simulations (field 1). In Ormarsson and Johansson (2006), a finite element simulation was performed to simulate progressive growth stress evolution in growing trees. These simulations were based on material data for Radiata pine and maturation strain data modelled by Yamamoto (1998). The second growth stress variation used here was based on this modelling work (field 2). For the third radial variation, Kubler's $(1959 ; 1987)$ classical model for radial variation in growth stresses was chosen (field 3). For Kubler's model a circumferal growth stress of $3 \mathrm{MPa}$ was assumed, and the compressive stresses close to the pith were limited to $12 \mathrm{MPa}$. The curve expressions used in the simulations are shown in equations (1-3) and illustrated in Figure 3. The equations use the ratio between actual radius $(r)$ and the radius of the $\log (R=160)$ as a parameter. The growth stresses in transversal directions were not included in the model.

Field 1 (Alhasani, 1999)

$$
G S=-3.5988+4.8222 \frac{r}{R}+0.9056\left(\frac{r}{R}\right)^{2}
$$

Field 2 (Ormarsson and Johansson, 2006)

$$
G S=-5.6049+1.107 \frac{r}{R}+21.329\left(\frac{r}{R}\right)^{2}-13.144\left(\frac{r}{R}\right)^{3}
$$

Field 3 (Kubler, 1959; Kubler, 1987)

$$
G S=3\left(1+2 \ln \left(\frac{r}{R}\right)\right), \quad G S=-12, \quad \frac{r}{R}<0.08 .
$$

For the parametric study a set of $81 \log$ analyses were run, one for each combination of parameters. The distortion of the boards, after releasing the boards from the log and after drying of the boards, was extracted. The twist, spring and bow were calculated from the nodal displacement according to Figure 4 . The twist is given in $\left({ }^{\circ}\right)$ per $2.5 \mathrm{~m}$ 


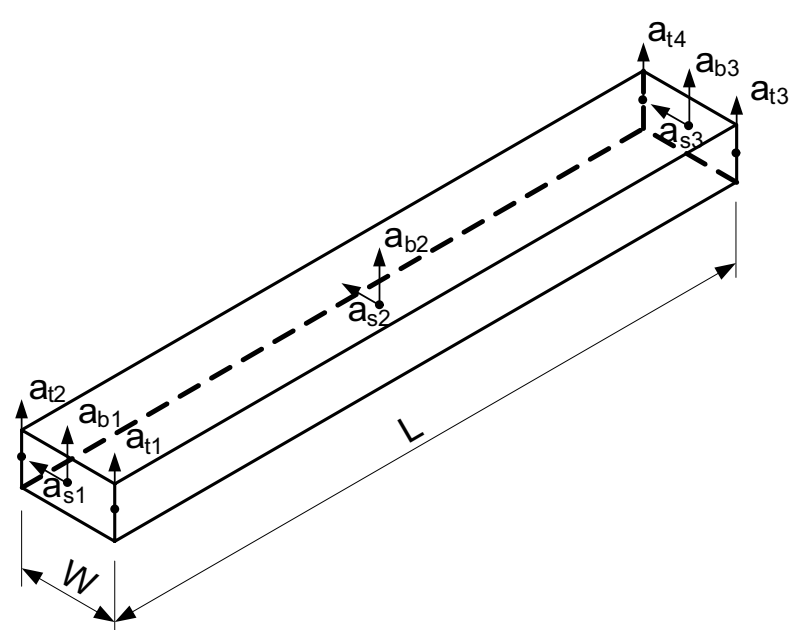

Twist

$\varphi_{\mathrm{twist}}=\operatorname{atan} \frac{a_{\mathrm{t} 1}-a_{\mathrm{t} 2}}{W}-\operatorname{atan} \frac{a_{\mathrm{t} 3}-a_{\mathrm{t} 4}}{W}$

Bow

$a_{\mathrm{bow}}=\frac{a_{\mathrm{b} 1}+a_{\mathrm{b} 3}}{2}-a_{\mathrm{b} 2}$

Spring

$a_{\text {spring }}=\frac{a_{\mathrm{s} 1}+a_{\mathrm{s} 3}}{2}-a_{\mathrm{s} 2}$

Figure 4. Definition of degrees of freedom used to calculate twist, bow and spring deformations.

board length, and the bow and spring are given in [mm] per $2.5 \mathrm{~m}$ board length.

The distortion data were analysed using the software SPSS 13.0. The studies of main effects and interactions were studied using univariate general linear models (GLM). In these studies the material parameters were set as categorical data for each curve. The model was run as a full factorial model containing all main effects and all factor-by-factor interactions. Profile plots were used to study the interactions between the different parameters.

\section{RESULTS}

For most of the studied boards, the results showed significant bow and/or spring deformations directly after sawing. Due to the symmetry of the annual rings, almost no bow and spring deformation occurred in board type $\mathrm{D}$ and board types $A$ and $B$ respectively. Twist was almost zero directly after sawing for all the four board types; see Figure 5a. During the drying, the amount of twist changed significantly. After the drying board type A was severely twisted, the other three boards were also twisted to a lesser degree but all by approximately the same amount; see Figure 5b. The distortion was, however, affected by both annual ring pattern and material parameters.

\subsection{Bow}

The mean bow deformations after sawing became largest for board type A and slightly lower for board types B and C; see Table I. Board type D showed almost zero bow, which was expected from a board with standing annual rings. During drying, the mean bow of board type A increased almost $2 \mathrm{~mm}$, while for board types B and C the increase was approximately $1 \mathrm{~mm}$. The standard deviation was largest for board type A, and it increased for all the board types during the drying.

The GLM analysis showed that the dominating factor in explaining the variation in bow directly after sawing for board
Table I. Mean (and standard deviation) bow (in $\mathrm{mm}$ per $2.5 \mathrm{~m}$ board length) of board types A-D after sawing and after drying.

\begin{tabular}{lcccc}
\hline Board & A & B & C & D \\
\hline After sawing & $5.98(4.33)$ & $4.31(1.97)$ & $3.87(1.73)$ & $0.00(0.00)$ \\
After drying & $7.93(5.04)$ & $5.27(3.42)$ & $4.90(3.00)$ & $0.00(0.01)$ \\
\hline
\end{tabular}

types A-C was the interaction between the growth stress field and the variation in modulus of elasticity. The results showed that the low variation in MOE resulted in higher values of bow, and the growth stress field 3 generated the highest mean bow while growth stress field 1 resulted in the lowest mean bow. The influence of the other parameters was much smaller; there were, however, effects of the interactions between the growth stress field and the variation in spiral grain angle, as well as the interaction between variation in MOE and variation in spiral grain angle. The effects of these parameters changed slightly when looking at the different board types separately.

Figure 6 displays mean bow deformation for board types A and B directly after sawing split by the different growth stress fields and the different MOE variations. For both the board types (A and B) the results showed clearly that the low variation in MOE resulted in a larger bow deformation. The growth stress fields had a different influence on the bow deformation. For board type A (closest to the pith) the highest mean bow could be found for growth stress field 3, whereas for board type B it occurred for growth stress field 2.

In many earlier experimental studies it has been shown that the variation in longitudinal shrinkage is one of the most important factors for the moisture-related change in bow (and spring) during drying. In this study, the effect of all the four different parameters proved to have significant influences on the change in bow deformation during drying, although to a different degree for different board types.

For board type A, the parameter with the largest effect on change in bow was the variation in longitudinal shrinkage. The 


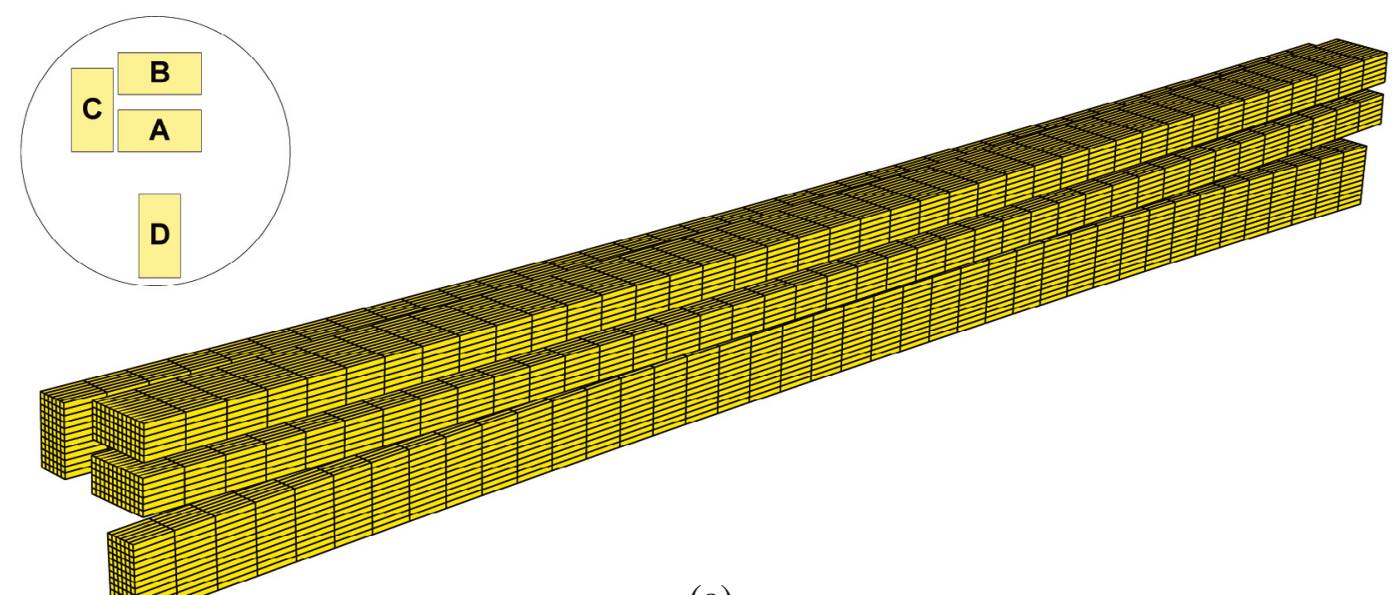

(a)

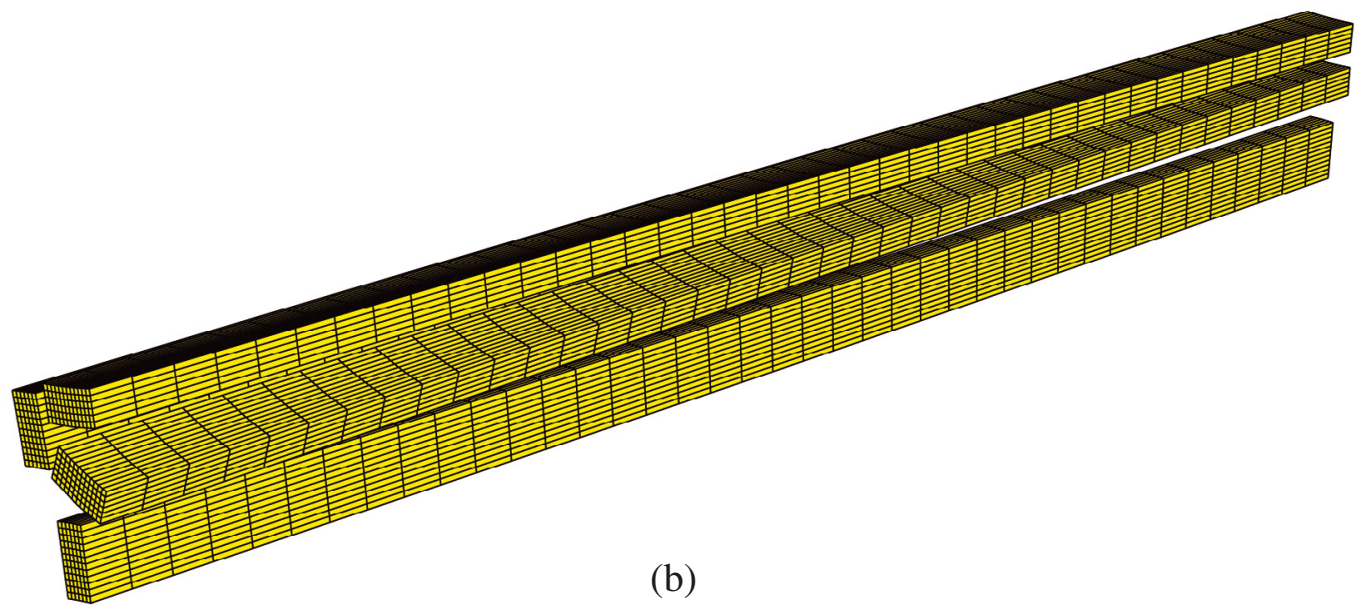

Figure 5. Simulated board deformations (magnified by factor of 3) (a) directly after the sawing (b) after the drying.

effect of variation in spiral grain angle was also large; see Figure 7a. The low variation in longitudinal shrinkage (decreasing value with distance from the pith, see Fig. $2 b$ ) resulted in a decreasing bow value during drying, except in combination with high spiral grain angle variation. For both the other two longitudinal shrinkage variations, the bow value increased during drying. There were also small effects of the growth stress field and variation in modulus of elasticity on the moisture-related change in bow. The change in bow increased more with growth stress field 3 than with the other growth stress fields, as well as with low modulus of elasticity.

For board type B, the effect of the different parameters on bow was more complex. The main effects and their interactions were more similar in size. The parameter variations that had the strongest influence were variation in spiral grain angle and in the longitudinal shrinkage coefficient. Figure $7 \mathrm{~b}$ shows that the low variation in longitudinal shrinkage caused a decrease in bow. The medium spiral grain angle variation (almost straight fibres, see Fig. 2a) caused a large decrease in bow when combined with the low or medium variation in longitudinal shrinkage. When combined with the high variation in longitudinal shrinkage, the increase in bow was much smaller than for the other two variations in spiral grain angle; see Figure 7b. For board type B there were also small differences in change of bow due to growth stress field and variation in modulus of elasticity. The change in bow was larger for stress field 2 than for the other stress field, and larger for the low variation in MOE. Board type $\mathrm{C}$ behaves quite similarly to board type $\mathrm{B}$, although the main effect of longitudinal shrinkage variation was stronger than for board type B.

The final bow deformation was a combination of deformations that occur during both sawing and drying. The final bow deformation was affected by all parameters studied. The interaction between the growth stress field and variation in modulus of elasticity was the most important parameter for the bow after sawing, whereas the effect of variation in longitudinal shrinkage and spiral grain angle was large during the drying process.

\subsection{Spring}

With the sawing pattern used in this study, only board types $\mathrm{C}$ and D received any spring deformation; see Table II. Board 
Board A

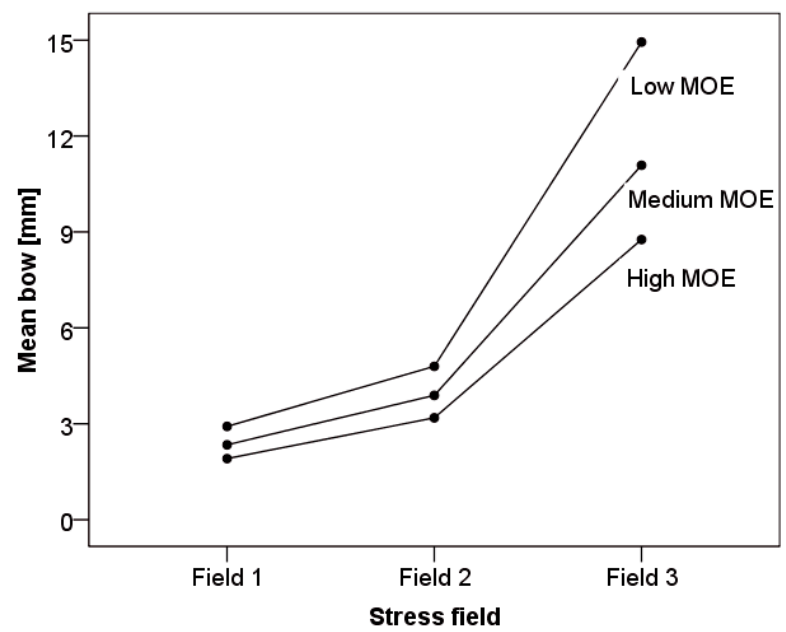

(a)

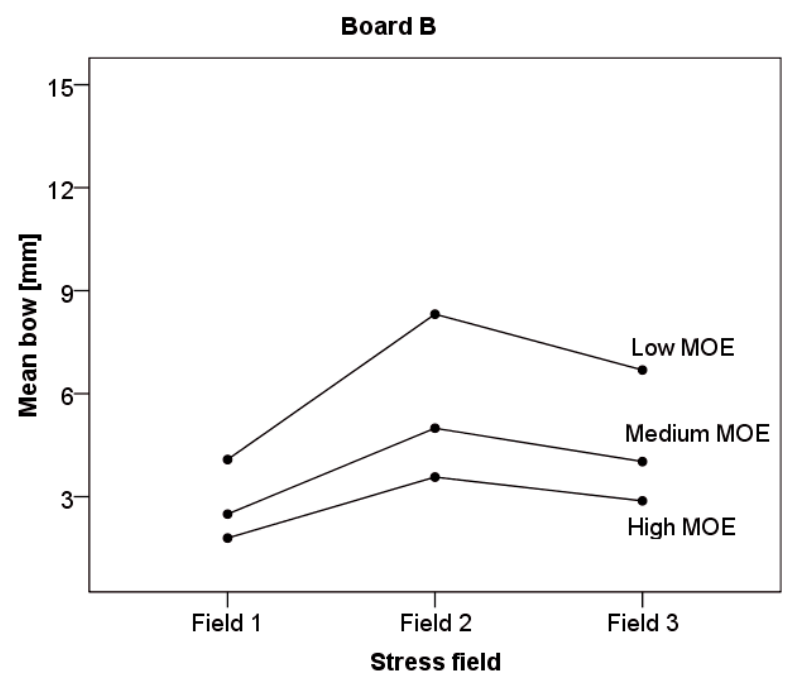

(b)

Figure 6. Influence of growth stress field and variation in MOE on the mean bow deformation after sawing, (a) for board type A and (b) for board type B.

Table II. Mean spring (standard deviation) in board types A-D after sawing and after drying (in mm per $2.5 \mathrm{~m}$ board length).

\begin{tabular}{lcccc}
\hline Board & A & B & C & D \\
\hline After sawing & $0.00(0.00)$ & $0.00(0.00)$ & $2.43(1.13)$ & $4.87(2.22)$ \\
After drying & $-0.02(0.00)$ & $0.00(0.00)$ & $3.11(1.91)$ & $5.70(3.70)$ \\
\hline
\end{tabular}

types A and B were symmetric flat-sawn boards (except for the spiral grain pattern) which resulted in very little spring deformation.

The influence of the parameter variations was very similar to the results for bow. The spring deformation directly after sawing was very much governed by the combination of growth stress field and the variation in modulus of elasticity. For board

\section{Board A}

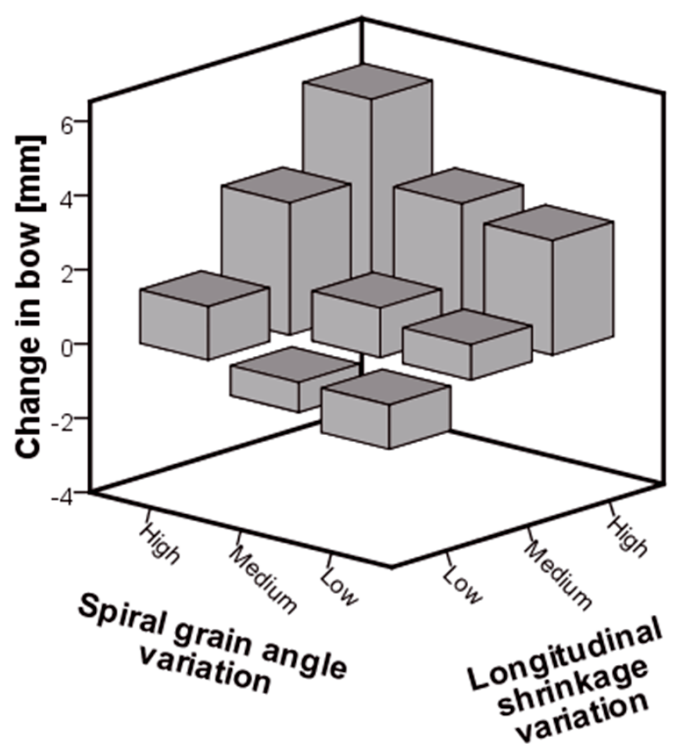

(a)

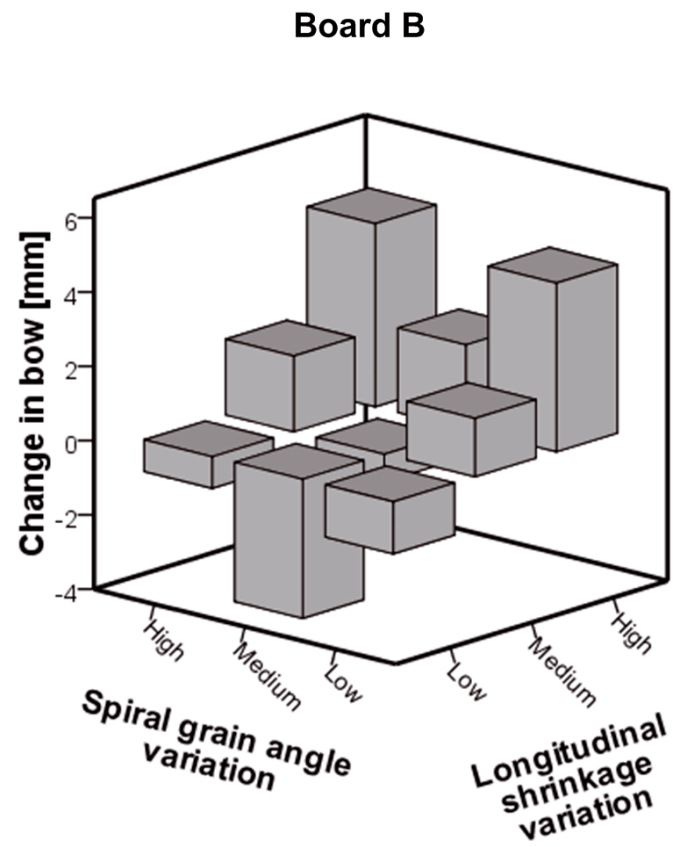

(b)

Figure 7. Influence of spiral grain and longitudinal shrinkage variation on mean change in bow during drying, (a) for board type A and (b) for board type B.

types $\mathrm{C}$ and $\mathrm{D}$, the most spring could be found for growth stress field 2, and the spring was larger for boards with low variation in modulus of elasticity.

The change in deformation during drying was to a high degree caused by the variation in longitudinal shrinkage. With the low variation in longitudinal shrinkage, the spring decreased. With the medium and high variation in longitudinal 


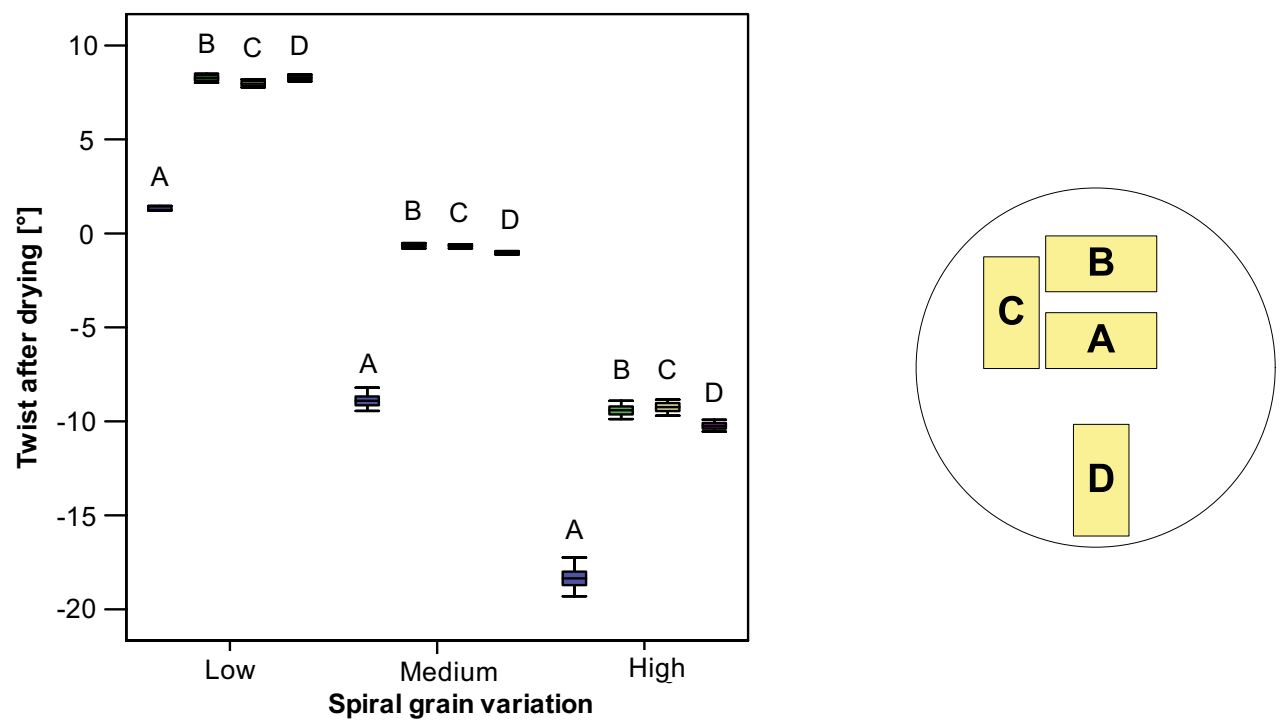

Figure 8. Influence of spiral grain variation on the final twist deformation (including both sawing and drying).

Table III. Mean twist (standard deviation) in board types A-D after sawing and after drying (in ${ }^{\circ}$ per $2.5 \mathrm{~m}$ board length).

\begin{tabular}{lcccc}
\hline Board & A & B & C & D \\
\hline After sawing & $0.15(0.21)$ & $0.09(0.16)$ & $0.08(0.13)$ & $0.06(0.08)$ \\
After drying & $-8.66(8.10)$ & $-0.60(7.26)$ & $-0.65(7.08)$ & $-1.00(7.61)$ \\
\hline
\end{tabular}

shrinkage, the spring increased except for the medium variation in longitudinal shrinkage in combination with medium spiral grain angle variation; cf. the change in bow for board type B. The influence of the other two parameters on the change in spring was very small.

As for the bow, the final spring deformation was very much influenced by all four of the studied parameters. In the sawing step, the growth stress field and the variation in modulus of elasticity could explain the main part of the spring deformation, whereas change in spring during drying could largely be explained by the two parameters of longitudinal shrinkage and spiral grain angle.

\subsection{Twist}

The twist generally was very small directly after sawing; see Table III. The twist value varied between $-0.18^{\circ}$ and $0.69^{\circ}$ for the individual boards. The largest twist was found in a board of type A, with growth stress field 3, high spiral grain angle variation and high MOE variation. The GLM analysis showed that the interaction between growth stress field and spiral grain angle variation was the most significant factor for the twist after sawing. Generally the twist became largest for boards sawn from a log with growth stress field 3 and the high spiral grain angle variation as well as the high variation in MOE.
During drying most of the boards became significantly twisted; see Table III. Although the mean twist values are small for board types B, C and D, the standard deviations were large, showing that many of the boards were severely twisted. The variation in spiral grain angle had the absolutely largest influence on the amount of twist after drying; see Figure 8. When dividing the results by the spiral grain angle variation, almost all the variation within each group disappeared. The high spiral grain angle variation resulted in negative twist for all the four board types. For the medium spiral grain angle variation, the twist of board types B-D became almost zero and negative for board type A. The low spiral grain angle variation led to positive twist in board types B-D and to almost zero twist for board type A. The twist difference between board type A and the other three board types was between $8-10^{\circ}$ for all spiral grain cases.

When dividing the results for the other parameters it was possible to see small differences between the different groups. Dividing the twist results according to growth stress field showed that boards simulated with growth stress field 3 exhibited slightly lower mean twist than the boards simulated with the other two growth stress fields. For board type A, the average twist became, for example, $-8.32^{\circ}$ for growth stress field 3 and $-8.82^{\circ}$ for the other two growth stress fields. This difference was smaller for the other board types.

\section{DISCUSSION}

The simulations showed that the parameters used in the analysis were very important for the distortions of sawn timber. For bow it could be seen that both the growth stress distribution and the modulus of elasticity were important factors to explain the variation in bow (and spring) after sawing. With growth stress field 1, which was measured on Norway spruce trees, the mean bow was $1.9 \mathrm{~mm}$ directly after sawing for all 
the boards. This is in accordance with results of bow measured directly after sawing on 24 boards of Norway spruce of the same dimension, mean bow $1.7 \mathrm{~mm}$ (Johansson and Ormarsson, 2005). The results also showed that the most important factor was the gradient in growth stress over the board. For board type B the largest bow could be found for growth stress field 2, which had the largest gradient in the area of the log where board type B was located, even when the absolute value of growth stress was similar for all three growth stress fields. The largest bow for board type A could be found with growth stress field 3, which had the largest gradient close to the pith. The non-existent bow in board type $\mathrm{D}$ was caused by the vertical symmetry resulting in no variation in growth stresses over the board thickness. Boards with a low modulus of elasticity received larger bending deformations than boards with high bending stiffness.

During drying, the longitudinal shrinkage variation with a negative gradient in the radial direction will normally change the bow in the opposite direction to the bow deformation caused by release of the growth stresses. This means that the final bow deformation after drying can be quite small if the effect of release of growth stresses during sawing and the effect of shrinkage during drying are of similar magnitude. There was, however, quite a large effect from the spiral grain angle variation on these results. A varying spiral grain angle over the cross-section of the board can decrease the effect of the axial component of the longitudinal shrinkage and therefore affect the bow (and spring). The growth stress field had a small effect on the change in bow and spring during drying. In the simulation a very slow drying was simulated, i.e. no moisture gradient was treated over the cross-section. With a harder drying regime the effect of creep and mechano-sorption would be larger. For such a drying regime the effect of the growth stresses in the board probably would be larger.

The final bow and spring of the boards after drying were affected by all the varied parameters. To minimise the bow and spring deformations, it is advantageous to have a growth stress variation with a small gradient, i.e. like the one measured by Alhasani. It is also beneficial to have a high modulus of elasticity as this will minimise the effect of the growth stresses. A small radial variation in longitudinal shrinkage is also advantageous as well as a straight grain. Kubler's growth stress field results in very large bow deformations, more than is normally reached in Swedish sawn timber. This curve is probably too steep to be representative for the growth stresses in Norway spruce. Kubler's original model does not take creep and relaxation into account; if these effects were included, the curve would probably be less steep and represent the real growth stress pattern better.

For twist, this study confirmed earlier studies in showing that the important parameters are spiral grain angle and its variation and distance from the pith. The high (left-handed) variation in spiral grain angle resulted in severe twist in all boards; the low spiral grain angle variation resulted in severe twist for boards sawn away from the pith. The parameter, distance from the pith, was important as it was possible to show that twist was of the same magnitude for boards cut at the same distance from the pith regardless of their orientation within the $\log$ (board types B, C and D). The other parameters had very small influence on the twist deformation.

This simulation was done without external load which can generate or reduce the distortion; boards loaded with external weight during the drying process would result in other and probably smaller distortions.

\section{CONCLUSIONS}

The parametric analysis performed in this study showed the relationships between different parameters (growth stresses, longitudinal shrinkage coefficient, spiral grain angle and modulus of elasticity) and the distortion of boards directly after sawing and after drying. The FEM simulations showed that bow (and spring) developed directly after sawing due to a combination of growth stresses and modulus of elasticity. The amount of bow and spring varied depending on type of growth stress field and variation in modulus of elasticity as well as position of the board within the log. During drying, both bow and spring changed due to effects of longitudinal shrinkage, but the results were also affected by the spiral grain angle. The final deformation was therefore a result of the combination of all four of the tested parameters. Twist was very small directly after sawing but increased very much during drying. The variation in twist in the boards could be explained almost fully by the variation in spiral grain angle and the distance between the centre of the board and the centre of the log.

FEM simulations proved to be a powerful tool for examining to what extent different input parameters influence the deformations of sawn timber during processing. The study also showed that growth stresses are a very important explanation for the bending distortion of timber. The effect was significant also for a species such as Norway spruce with moderate growth stresses. The results from the simulations with this growth stress field showed that the release of these relatively small growth stresses causes a large portion of the final bending deformations, and that this effect is at least as important as the effect of shrinkage.

The investigation has demonstrated that numerous parameters contribute to the development of distortion in sawn timber. Many of these parameters are, however, possible to change either in the forest or in the saw-mill process. By changing the genetic material used in the forest or by different silvicultural practice, it should be possible to obtain timber products better suited for the end user's needs.

Acknowledgements: The authors gratefully acknowledge the financial support from FORMAS, The Swedish Research Council for Environment, Agricultural Sciences and Spatial Planning.

\section{REFERENCES}

Alhasani M.A., 1999. Growth stresses in Norway spruce, Licentiate, Lund University, Lund,

Archer R.R., 1987. Growth stresses and strains in trees, Springer Verlag, Berlin, 
Backstrom M. and Johansson M., 2006. Analytical model of twist in Norway spruce (Picea abies) timber. Scand. J. For. Res. 21: 54-62.

Balodis V., 1972. Influence of grain angle on twist in seasoned boards. Wood Sci. Technol. 5: 44-50.

Booker R.E., 2005. Geometric model to predict twist in unrestrained boards. Wood Sci. Technol. 39: 269-289.

Dahlblom O., Petersson H., and Ormarsson S. (2000). Characterisation of longitudinal shrinkage coefficient, Final report Sub-task AB1.7. FAIR CT96-1915 Improved Spruce Timber Utilization, Lund, Lund University, Division of Structural Mechanics.

Eastin I.L., Shook S.R., and Fleishman S.J., 2001. Material substitution in the US residential construction industry, 1994 versus 1998. For Prod. J. 51: 30-37.

Eastin I.L., Shook S.R., and Simon D.D., 1999. Softwood lumber substitution in the US residential construction industry in 1994. For. Prod. J. 49: 21-27.

Fang C.H., Guibal D., Clair B., Gril J., Liu Y.M, and Liu S.Q., 2008. Relationship between growth stress and wood properties in poplar I69 (Populus deltiodes Bartr. cv. "Lux" ex I-69/55). Ann. For. Sci. 65: 307.

Johansson M., 2003. Prediction of bow and crook in timber studs based on variation in longitudinal shrinkage. Wood Fiber Sci. 35: 445-455.

Johansson M. and Kliger R., 2002. Influence of material characteristics on warp in Norway spruce studs. Wood Fiber Sci. 34: 325-336.

Johansson M. and Ormarsson S. (2005). Effect of residual stresses on perfomance of sawn timber - experiments. Fifth Workshop IUFRO 5.01.04, Waiheke Island, New Zealand.

Johansson M., Perstorper M., Kliger R., and Johansson G., 2001. Distortion of Norway spruce timber Part 2. Modelling twist. Holz Roh- Werkst. 59: 155-162.

Kliger R., Johansson M., and Perstorper M., 1997. Influence of threedimensional variation in shrinkage on distortion. International conference of Cost Action E8, Mechanical Performance of Wood and Wood Procducts, Copenhagen, Denmark.

Kliger R., Johansson M., Perstorper M., and Johansson G., 2003. Distortion of Norway spruce timber - Part 3: Modelling bow and spring. Holz Roh- Werkst. 61: 241-250.

Kubler H., 1959. Studies on growth stress in trees - Part II: Longitudinal stresses (Studien über Wachstumsspannung des Holzes - zweite
Mitteilung: Die Spannung in Faserrichtung); (in German). Holz RohWerkst. 17: 44-54.

Kubler H., 1987. Growth stresses in trees and related wood properties. For. Prod. Abstr. 10: 62-119.

Mishiro A. and Booker R.E., 1988. Warping in new crop radiata pine $100 \times 50 \mathrm{~mm}(2$ by 4$)$ boards. Bulletin of Tokyo University Forests 80: $37-68$.

Moore G.L. and Maun K.W. (1998). Measurement of spiral grain on discs, project report sub-task AB1.6. FAIR CT96-1915 improved spruce timber utilization watford, building research establishment.

Okuyama T. and Sasaki Y., 1979. Crooking during lumbering due to residual stresses in the tree. Mokuzai Gakkaishi 25: 681-687.

Ormarsson S., Dahlblom O., and Johansson M., 2008. Finite element study of growth stress formation in wood and related distortion of sawn timber. Wood Sci. Technol. DOI 10.1007/s00226-0080209-2.

Ormarsson S., Dahlblom O., and Petersson H., 1998. A numerical study of the shape stability of sawn timber subjected to moisture variation - Part 1: Theory. Wood Sci. Technol. 32: 325-334.

Ormarsson S., Dahlblom O., and Petersson H., 1999. A numerical study of the shape stability of sawn timber subjected to moisture variation Part 2: Simulation of drying board. Wood Sci. Technol. 33: 407-423.

Ormarsson S., Dahlblom O., and Petersson H., 2000. A numerical study of the shape stability of sawn timber subjected to moisture variation Part 3: Influence of annual ring orientation. Wood Sci. Technol. 34: 207-219.

Ormarsson S. and Johansson M., 2006. Finite element simulation of growth stresses and related board distortions caused by sawing and forced drying. N. Z. J. For. Sci. 36: 408-423.

Stanish M.A., 2000. Predicting the crook stability of lumber within the hygroscopic range. Dry. Technol. 18: 1879-1895.

Stevens W.C. and Johnston D.D., 1960. Distortion caused by spiralled grain. Timber Technol. 68: 217-218.

Woxblom L., 1993. Quality variations in wall studs - A study conducted at five sawmills in southern Sweden (in Swedish), Licentiate, Swedish University of Agricultural Sciences, Uppsala.

Yamamoto H., 1998. Generation mechanism of growth stresses in wood cell walls: Roles of lignin deposition and cellulose microfibril during cell wall maturation. Wood Sci. Technol. 32: 171-182. 


\section{ANNEXE}

Table A. Material parameters used in all the simulations.

\begin{tabular}{|c|c|c|c|}
\hline Elastic strain & $E_{10}=$ see Figure $2 \mathrm{c}$ & $E_{\mathrm{r} 0}=400 \mathrm{MPa}$ & $E_{\mathrm{t} 0}=220 \mathrm{MPa}$ \\
\hline Parameters & $E_{\mathrm{lw}}=21000 \mathrm{MPa}$ & $E_{\mathrm{rw}}=2200 \mathrm{MPa}$ & $E_{\mathrm{tw}}=1300 \mathrm{MPa}$ \\
\hline & $G_{\mathrm{lr} 0}=400 \mathrm{MPa}$ & $G_{\mathrm{lt} 0}=250 \mathrm{MPa}$ & $G_{\mathrm{rt} 0}=25 \mathrm{MPa}$ \\
\hline & $G_{\mathrm{lrT}}=0.013{ }^{\circ} \mathrm{C}^{-1}$ & $G_{\mathrm{ltT}}=0.013^{\circ} \mathrm{C}^{-1}$ & $G_{\mathrm{rtT}}=0.013{ }^{\circ} \mathrm{C}^{-1}$ \\
\hline & $v_{\mathrm{lr}}=0.35$ & $v_{\mathrm{lt}}=0.6$ & $v_{\mathrm{rt}}=0.55$ \\
\hline $\begin{array}{l}\text { Moisture-induced } \\
\text { Parameters }\end{array}$ & $\alpha_{1}=$ see Figure $2 \mathrm{~b}$ & $\alpha_{\mathrm{r}}=0.19$ & $\alpha_{\mathrm{t}}=0.35$ \\
\hline Strain parameters & $\begin{array}{l}m_{\mathrm{l} r 0}=0.008 \mathrm{MPa}^{-1} \\
\mu_{\mathrm{lr}}=0\end{array}$ & $\begin{array}{l}m_{\mathrm{lt} 0}=0.008 \mathrm{MPa}^{-1} \\
\mu_{\mathrm{lt}}=0\end{array}$ & $\begin{array}{l}m_{\mathrm{rt} 0}=0.8 \mathrm{MPa}^{-1} \\
\mu_{\mathrm{rt}}=1.0\end{array}$ \\
\hline
\end{tabular}

